DOI https://doi.org/10.15589/znp2020.4(482).5

УДК 621.313

\title{
EQUILIBRIUM BALANCING METHOD AND AUTOMATION OF CALCULATIONS OF THE STABLE MODE OF THE ELECTRICAL NETWORK
}

\section{МЕТОД РІВНОВАЖНОГО БАЛАНСУВАННЯ ТА АВТОМАТИЗАЦІЯ РОЗРАХУНКІВ УСТАЛЕНОГО РЕЖИМУ ЕЛЕКТРИЧНОЇ МЕРЕЖІ}

\author{
Svitlana V. Bevz \\ bevz@vntu.edu.ua \\ ORCID: 0000-0001-5561-9036 \\ Sergii M. Burbelo \\ burbelo@vntu.edu.ua \\ ORCID: 0000-0002-8554-2292 \\ Viktoriia V. Voitko \\ dekanfki@i.ua \\ ORCID: 0000-0002-3329-7256
}

\author{
С. В. Бев3, \\ канд. техн. наук, доцент
}

С. М. Бурбело,

канд. техн. наук, доцент кафедри ПЗ

В. В. Войтко,

канд. техн. наук, доцент

\section{Vinnytsyia National Technical University, Vinnytsia \\ Вінницький національний технічний університет, м. Вінниця}

\begin{abstract}
The article develops a new method of equilibrium power balancing of the power system. This method performs the calculation of the electrical network without allocating a balancing node in the network diagram.

The aim is to refine the calculation of steady state under the imbalance of generated and consumed power of the power system by reducing the error of calculation of currents in the branches by determining the weighted average current vector, which will increase the accuracy of calculations and increase the speed of calculation processes in the power system.

The developed method allows distributing of the existing imbalance evenly across all nodes. The proposed approach causes the refusal to define a separate balancing node in the scheme, the calculations of which lead to errors. According to the developed method of equilibrium power balancing, the imbalance will be distributed between all nodes of the circuit. The current in the branches of the circuit will have a value that can be obtained by calculating the steady state by the classical method as the average value of the currents determined in the calculation of all variants of different balancing nodes. To bring the system of generalized equations to the canonical form, an additional equilibrium reference current variable in the form of an additional column of ones and an additional column of zeros in the incidence matrix compiled according to Kirchhoff's second law should be added to all equations of Kirchhoff's first law.

As a result, the algorithm of the method is developed, the structure of which is linear, and the method itself is easy to use. Means of automation of calculations of the steady-state mode of an electric network in the environment of a package of MathCAD applications are also developed.

The scientific novelty is the refusal to allocate a balancing unit in the electrical network when calculating the steady state with equilibrium power balancing of the power system, which increases the accuracy of the calculation by applying the approach to determine the weighted average vector of currents.

The practical significance of the results is that the application of the proposed method for equilibrium balancing of nodes allows reducing of the calculation time and increase accuracy compared to the classical approach, which focuses on the introduction of balancing node, power change in which to maintain equilibrium power between generators and system loads. A significant increase in the speed of calculation processes in the power system by reducing iterative calculations and increasing the accuracy of calculations by reducing the error in calculating currents in the branches by determining the weighted average current vector is the main advantage of the developed method of equilibrium power balancing. The proposed method of equilibrium balancing can be used independently when calculating the electrical network.
\end{abstract}

Key words: capacity balancing; electrical network; balancing node; incidence matrix; Kirchhoff's laws.

Анотація. У статті розроблено новий метод рівноважного балансування потужності електроенергетичної системи. Цей метод виконує розрахунок електричної мережі без виділення балансувального вузла в схемі мережі. 


\section{ЕЛЕКТРОЕНЕРГЕТИКА, ЕЛЕКТРОТЕХНІКА ТА ЕЛЕКТРОМЕХАНІКА № 4 — 2020}

Метою роботи є уточнення розрахунку усталеного режиму за умови небалансу генерованої та спожитої потужності електроенергетичної системи шляхом зменшення похибки розрахунку струмів у вітках через визначення середньозваженого вектора струмів, що підвищить точність обчислень, та збільшення швидкодії розрахункових процесів в електроенергетичній системі шляхом зменшення кількості ітераційних обчислень.

Розроблений метод дає змогу розподілити наявний небаланс рівномірно за всіма вузлами. Запропонований підхід зумовлює відмову від визначення окремого балансувального вузла в схемі, розрахунки за яким призводять до появи похибок. За розробленим методом рівноважного балансування потужностей небаланс розподілиться між усіма вузлами схеми. Водночас струм у вітках схеми буде мати значення, яке може бути отримане під час розрахунків усталеного режиму за класичним методом як середнє значення струмів, визначених під час розрахунку всіх варіантів різних балансувальних вузлів. Для приведення системи узагальненого рівняння до канонічного вигляду в усі рівняння першого закону Кірхгофа треба додати додаткову змінну рівноважного задаючого струму у формі додаткового стовпця одиниць і додаткового стовпця нулів у матриці інцидентності, що складена за другим законом Кірхгофа.

У результаті роботи розроблено алгоритм методу, структура якого є лінійною, а сам метод $є$ простим у використанні. Також розроблено засоби автоматизації розрахунків усталеного режиму електричної мережі в середовищі пакету прикладних програм MathCAD.

Наукова новизна полягає у відмові від виділення балансувального вузла в схемі електричної мережі під час розрахунку усталеного режиму з рівноважним балансуванням потужності електроенергетичної системи, що забезпечує підвищення точності розрахунку завдяки застосуванню підходу щодо визначення середньозваженого вектора струмів.

Практичне значення результатів полягає в тому, що застосування запропонованого методу для рівноважного балансування потужностей вузлів дає змогу зменшити час розрахунку та підвищити точність порівняно 3 класичним підходом, який орієнтований на введення балансувального вузла, зміна потужності в якому допомагає підтримувати рівноважні потужності між генераторами та навантаженнями системи. Значне збільшення швидкодії розрахункових процесів в електроенергетичній системі шляхом зменшення ітераційних обчислень і підвищення точності обчислень завдяки зменшенню похибки розрахунку струмів у вітках через визначення середньозваженого вектора струмів $є$ головною перевагою розробленого методу рівноважного балансування потужностей. Запропонований метод рівноважного балансування може використовуватися самостійно під час розрахунку електричної мережі.

Ключові слова: балансування потужностей; електрична мережа; балансувальний вузол; матриця інцидентності; закони Кірхгофа.

\section{ПОСТАНОВКА ЗАДАЧІ}

За законом збереження енергії, який діє в електроенергетичній системі, у будь-який момент часу в цій системі повинен виконуватися баланс генерованих i спожитих потужностей з урахуванням втрат. Тож під час розрахунку усталеного режиму електричної мережі в розрахункову схему зазвичай вводиться балансувальний вузол, зміна потужності в якому уможливлює підтримку рівноважності потужностей між генераторами та навантаженнями. Класичний метод розрахунку призводить до суттєвих спотворень розрахункових струмів у вітках i, як наслідок, до неправильного розрахунку втрат потужності та значних небалансів у схемі. Тому актуальним $\epsilon$ пошук альтернативних розрахункових методів балансування потужностей, спрямованих як на підвищення швидкодії обчислень, так і на підвищення точності отриманих результатів.

\section{АНАЛІЗ ОСТАННІХ ДОСЛІДЖЕНЬ І ПУБЛІКАЦІЙ}

Відповідно до закону збереження енергії в електроенергетичній системі передбачається забезпечення балансу між генерованими та спожитими потужностями з урахуванням втрат. Розрахунок усталеного режиму електричної мережі за класичним методом зумовлює введення в розрахункову схему балансувального вузла. Зміна потужності в цьому вузлі забезпечує підтримку рівноважності потужностей між генераторами та навантаженнями системи $[1 ; 2]$.

Попри всі переваги такого традиційного нині підходу, ця розрахункова методика допускає суттєві спотворення струмів у вітках, що, зі свого боку, призводить до похибок в обчисленнях втрат потужності й появи значних небалансів у схемі. Крім іншого, існують випадки, коли класична постановка задачі розрахунку усталеного режиму з огляду на вибір балансувального вузла не є оптимальною та потребує корекції. Відповідно, розрахунок усталеного режиму в [3] здійснюється за методом Ньютона як без балансувального вузла, так і з декількома балансувальними вузлами. Введення в розрахункову модель із постійною частотою балансувального вузла може призвести не тільки до отримання розрахункового режиму, який не відповідає реальному режиму енергосистеми, а й до неможливості розрахунку усталеного режиму через обмеження пропускної здатності ліній електропередач, дотичних до балансувального вузла [4]. 
Тож науково-практичний інтерес дослідження полягає у проведенні аналізу впливу балансувального вузла на результати розрахунку усталеного режиму електроенергетичної системи, а також у розробленні нового підходу, моделі та методу розрахунку усталеного режиму, що дасть змогу уточнити розрахункові значення струмів у вітках і втрат потужності за наявності небалансу в системі.

\section{ВІДОКРЕМЛЕННЯ НЕ ВИРІШЕНИХ РАНІШЕ ЧАСТИН ЗАГАЛЬНОЇ ПРОБЛЕМИ}

Вибір балансувального вузла для розрахунку усталеного режиму електроенергетичної системи $\epsilon$ одним із чинників, які впливають на перебіг і точність розрахунку. Крім того, зміна балансувального вузла чинить вплив на перетоки потужностей і рівень втрат активної та реактивної потужності в системі. Проте розв'язання системи рівнянь усталеного режиму роботи електричної мережі передбачає відповідний прийом вилучення одного з рівнянь, що відповідає балансувальному вузлу, оскільки міра складності поставленої задачі становить -1 (кількість шуканих змінних менша на 1 від кількості рівнянь у системі). Така методика розрахунку передбачає накопичення всього небалансу потужності схеми в одному вузлі, що спотворює результати розрахунку за умови небалансу потужності генерації та споживання. Отже, перед нами постає задача розроблення методу врахування небалансу потужностей у розрахунку усталеного режиму роботи електроенергетичної системи.

\section{МЕТА ДОСЛІДЖЕННЯ}

Метою роботи $є$ уточнення розрахунку усталеного режиму за умови небалансу генерованої та спожитої потужності електроенергетичної системи шляхом зменшення похибки розрахунку струмів у вітках через визначення середньозваженого вектора струмів, що підвищить точність обчислень, та збільшення швидкодії розрахункових процесів в електроенергетичній системі через зменшення кількості ітераційних обчислень.

\section{МЕТОДИ, ОБ'СКТ ТА ПРЕДМЕТ ДОСЛІДЖЕННЯ}

У роботі використовуються методи розрахунку усталеного режиму роботи електроенергетичної системи. Метод рівноважного балансування потужностей передбачає відмову від визначення балансувального вузла. Для приведення системи узагальненого рівняння до канонічного вигляду використовуються рівняння законів Кірхгофа і матриці інцидентності для визначення балансів струмів і напруг в електричних схемах.

Об'єктом дослідження є процес розрахунку усталеного режиму роботи електроенергетичної системи. Предмет дослідження - методи балансування потужностей між генераторами та навантаженнями з урахуванням втрат.

\section{ОСНОВНИЙ МАТЕРІАЛ}

Розроблення методу рівноважного балансування потужностей. Під час розрахунку усталеного режиму роботи електроенергетичної системи метод рівноважного балансування потужностей виключає вибір балансувального вузла.

Баланс струмів у кожному вузлі визначається за першим законом Кірхгофа, який у матричній формі записується з використанням повної першої матриці інцидентності М [1]:

\section{$\mathbf{M} \cdot \dot{\mathbf{I}}=\dot{\mathbf{J}}$,}

де $\mathbf{\text { I }}$ - вектор-стовпець комплексних струмів у вітках;

j - вектор-стовпець задаючих струмів у вузлах системи.

Баланс напруг у контурах визначається за другим законом Кірхгофа та в матричному вигляді може бути записаний за допомогою другої матриці інцидентносTi $\mathbf{N}$ :

$$
\mathbf{N} \cdot \mathbf{Z} \mathbf{B} \cdot \dot{\mathbf{I}}=0,
$$

де $\mathbf{Z}_{\mathbf{B}}$ - діагональна матриця опорів віток.

Чи з врахуванням електрорушійної сили $\dot{\boldsymbol{E}}$ :

$$
\mathbf{N} \cdot \mathbf{Z}_{\mathbf{B}} \cdot \dot{\mathbf{I}}=\mathbf{N} \cdot \dot{\boldsymbol{E}} .
$$

Як відомо [1], узагальнене рівняння стану у матричній формі формується за першим і другим законом Кірхгофа та набуває вигляду:

$$
\boldsymbol{A} \cdot \dot{\mathbf{I}}=\dot{\boldsymbol{F}},
$$

у якому $\mathbf{A}=\left[\begin{array}{c}\mathbf{M} \\ \mathbf{N} \cdot \mathbf{Z} \mathbf{B}\end{array}\right] ; \mathbf{F}=\left[\begin{array}{c}\dot{\mathbf{J}} \\ \mathbf{N} \cdot \dot{\mathbf{E}}\end{array}\right]$.

Проте в цьому рівнянні використовується перша матриця інцидентності, тобто матриця, з якої вилучено один рядок, що відповідає балансувальному вузлу, оскільки міра складності цієї системи рівнянь рівна -1.

Пропонується якісно новий підхід стосовно розв'язання такої системи рівнянь, а саме приведення їі до канонічного вигляду шляхом додавання нової змінної в кожне 3 рівнянь, складених за першим законом Кірхгофа.

Отже, повна матриця інцидентності доповнюється справа стовпцем 3 одиницями, а матриця контурних опорів у вітках доповнюється справа стовпцем із нулями:

$$
\mathbf{M s}=\left[\begin{array}{ll}
\mathbf{M} & 1
\end{array}\right] ; \mathbf{Z s}=\left[\begin{array}{ll}
\mathbf{N} \cdot \mathbf{Z}_{\mathbf{B}} & 0
\end{array}\right] .
$$

Узагальнене рівняння стану набуде вигляду:

$$
A \boldsymbol{s} \cdot \dot{\mathbf{I}} \mathbf{s}=\dot{\boldsymbol{F}},
$$

у якому $\mathbf{A s}=\left[\begin{array}{c}\mathbf{M s} \\ \mathbf{Z s}\end{array}\right] ; \dot{\mathbf{I} s}=\left[\begin{array}{c}\mathbf{I} \\ \mathbf{J g}\end{array}\right]$.

Обернувши матрицю коефіцієнтів, отримаємо значення:

$$
\dot{\mathbf{I}} \mathbf{s}=\mathbf{A} \mathbf{s}^{-1} \cdot \dot{\mathbf{F}} .
$$

За умови виконання балансу спожитої та генерованої потужності у n вузлах: 


$$
\sum_{k=1}^{n} J_{i}=0
$$

результат розрахунку $\mathbf{J g}=0$, а струми у вітках, розраховані за класичним методом за різних балансувальних вузлів, однакові.

За умови небалансу потужностей у системі, тобто за:

$$
\sum_{k=1}^{n} J_{i} \neq 0
$$

результат розрахунку $\mathbf{J g} \neq 0$ і становить рівнозначну частку небалансу в кожному 3 вузлів схеми, а розраховані значення струмів у вітках $\dot{\boldsymbol{I}} \boldsymbol{s}$ дорівнюють середньому значенню струму у вітках $\dot{\boldsymbol{I}}_{\boldsymbol{k}}, \boldsymbol{k}=\overline{1, \boldsymbol{n}}$, що отримані під час класичних розрахунків за різними $\boldsymbol{k}$ балансувальними вузлами:

$$
\dot{\boldsymbol{I}} \boldsymbol{s}=\sum_{k=1}^{n} \dot{\boldsymbol{I}}_{\boldsymbol{k}} / \boldsymbol{n}
$$

де $\dot{\boldsymbol{I}}_{\boldsymbol{k}}-$ значення вектора струмів у вітках за класичним методом для $k$-го балансувального вузла..

Алгоритмізація методу. Розроблений метод рівноважного балансування потужностей спрямований на самостійне використання під час розрахунку усталеного режиму електричної мережі. Для цього необхідно відмовитися від визначення окремого балансувального вузла в схемі. За цим методом небаланс розподілиться між усіма вузлами схеми. Водночас струм у вітках схеми буде мати значення, яке може бути отримане в розрахунках усталеного режиму за класичним методом як середнє значення струмів, визначених під час розрахунку всіх варіантів різних балансувальних вузлів. На рис. 1 подано алгоритмічну реалізацію методу.

Як видно з алгоритму, зображеного на рис. 1, за класичним методом необхідно $\mathbf{n}$ разів здійснити розрахунок усталеного режиму за умови почергового вибору різних балансувальних вузлів $\boldsymbol{g r}\left(\boldsymbol{M}, \boldsymbol{V}_{\boldsymbol{k}}\right), \boldsymbol{g r}\left(\boldsymbol{J}, \boldsymbol{V}_{\boldsymbol{k}}\right)$, що задаються векторами $\boldsymbol{V}_{\boldsymbol{k}}$.

Структура ж алгоритму новоствореного методу $€$ лінійною, а сам метод простий у використанні. Для здійснення рівноважного балансування потужностей вузлів один розрахунок за новоствореним методом дає змогу замінити $\mathbf{n}$ розрахунків за класичним методом, що є суттєвою перевагою запропонованого методу.

Автоматизація розрахунку струмів у вітках за умови різних балансувальних вузлів засобами MathCAD. Визначення хорд за наявної повної матриці інцидентності доцільно здійснювати шляхом відбору відповідних стовпців матриці інцидентності, кількість ненульових елементів яких більша від одиниці. Тому за алгоритмом визначення

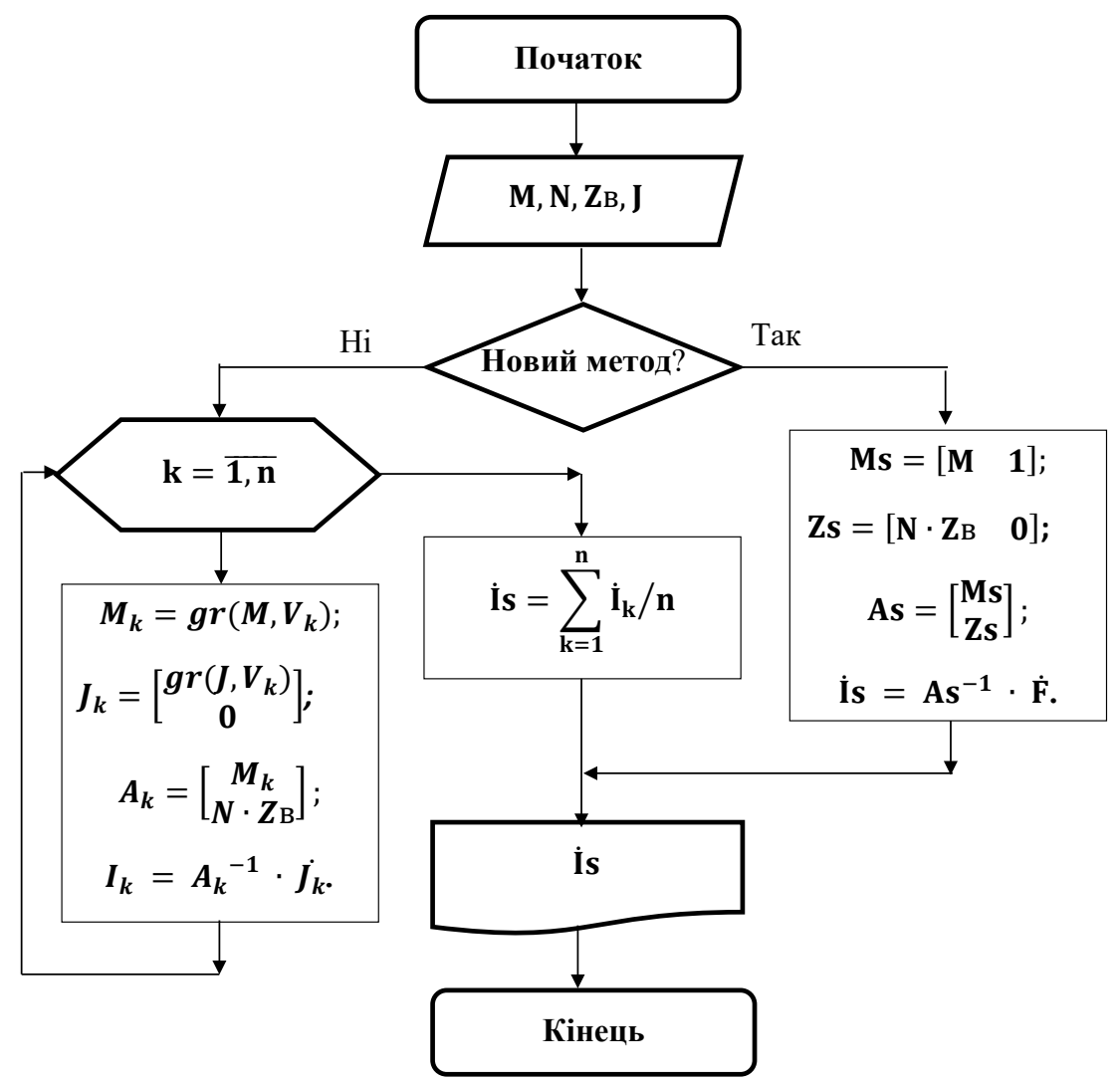

Рис. 1. Алгоритмічна реалізація методу розрахунку усталеного режиму роботи електроенергетичної системи 
хорд спочатку визначається масив $\boldsymbol{s}_{1}$ кількості ненульових елементів і масив $\boldsymbol{s}_{2}$ номерів вузлів відповідних віток. Для кожного стовпця виконується перевірка умови більшості від одиниці кількості ненульових елементів (або сум модулів елементів) рядків, у яких елементи цього стовпця відмінні від нуля. Якщо вищезазначена умова виконується, тоді вітку, що відповідає цьому стовпцю, відносимо до хорд у функції getHords(a) (див. рис. 2), в іншому разі вітка належить до дерева функцією tree(a) (див. рис. 3).
Функцію getDiff(m), що дає змогу сформувати n наборів номерів вузлів графа для різних балансувальних вузлів, та функцію getTree $(\boldsymbol{a}, \boldsymbol{b})$, яка здійснює вибір стовпців, що не належать до хорд у першій матриці інцидентності, подано на рис. 3.

Функція getColumns $(\boldsymbol{a}, \boldsymbol{h})$ здійснює розподіл матриці інцидентності на матрицю дерева графа Ма та матрицю хорд Мb. Функція getRows $(\boldsymbol{a}, \boldsymbol{h})$ відбирає рядки, які використовуватимуться в подальшому розрахунку, наприклад, без рядка, що відповідає балансувальному вузлу. Це проілюстровано на рис. 4.

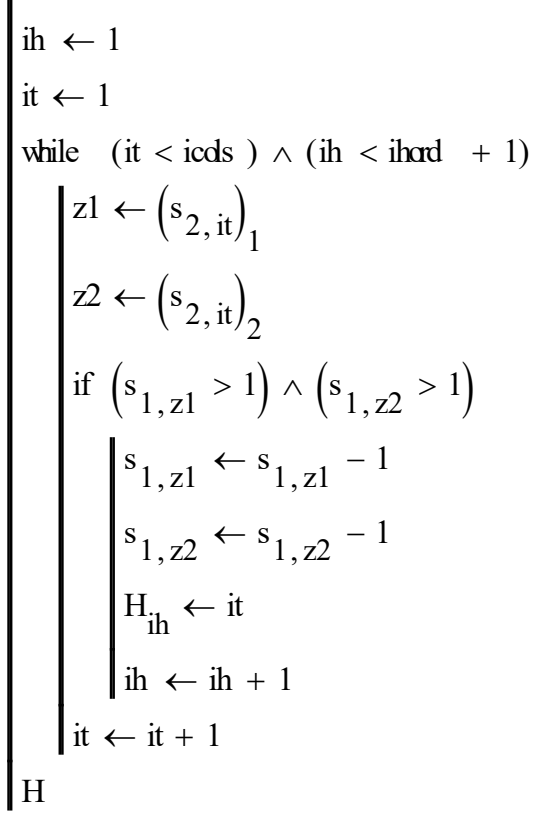

Рис. 2. Функція відбору хорд за першою матрицею інцидентності $\operatorname{getHords}(\boldsymbol{a})$

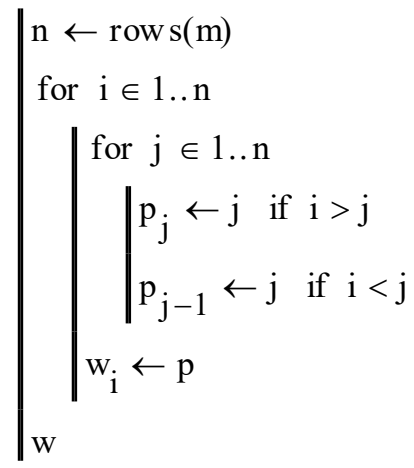

a) Функиія getDiff(m)

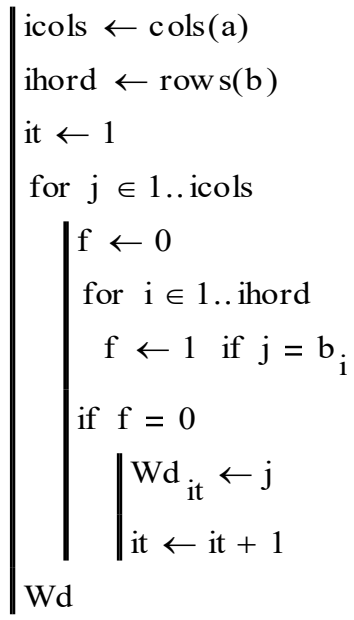

б) Функиія getTree $(m, h)$

Рис. 3. Функція формування номерів вузлів, крім балансувального, та функція відбору віток дерева (окрім віток хорд) за даними першої матриці інцидентності 
$\mid \begin{aligned} & \mathrm{n} \leftarrow \operatorname{row} \mathrm{s}(\mathrm{m}) \\ & \text { for } \mathrm{i} \in 1 . . \mathrm{n} \\ & \mid \begin{array}{l}\text { for } \mathrm{j} \in 1 . . \mathrm{n} \\ \mid \mathrm{p}_{\mathrm{j}} \leftarrow \mathrm{j} \text { if } \mathrm{i}>\mathrm{j} \\ \mathrm{p}_{\mathrm{j}-1} \leftarrow \mathrm{j} \text { if } \mathrm{i}<\mathrm{j} \\ \mathrm{w}_{\mathrm{i}} \leftarrow \mathrm{p}\end{array}\end{aligned}$

a) Функиія getColumns( $(, h)$

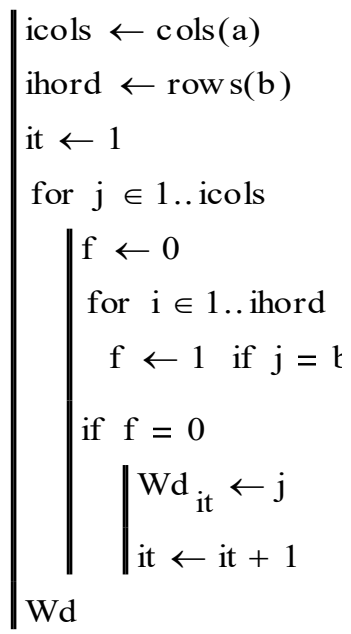

б) Функиія getRows $(a, h)$

Рис. 4. Функції формування матриці засобами вибору стовпців і рядків за вектором $h$ їхніх номерів

Для визначення підматриць першої матриці інцидентності для дерева та хорд скористаємося виразами:

Ma $=\operatorname{getColumns}(\mathbf{M w b}, \mathbf{D}), \mathbf{M b}=\operatorname{getColumns}(\mathbf{M w b}, \mathbf{H})$.

Визначення ж другої матриці інцидентності здійснюється як транспонована матриця стикування $[-\mathbf{M a}]^{-1} \cdot \mathbf{M b}$ та діагональної одиничної матриці getNDiag(M), що відповідає хордам графа. Зауважимо, що розмірність діагональної матриці визначається кількістю контурів, що, зі свого боку, залежить від кількості віток і вузлів схеми, як це проілюстровано функцією на рис. 5.

Отже, кількість контурів схеми на одиницю більша від різниці кількості віток і кількості вузлів схеми.

На рис. 6. наведено розрахунок струмів у вітках getRstate $(\mathrm{m}, \mathrm{n}, \mathrm{z}, \mathrm{v}, \mathrm{j})$ та вузлах getJBalance $(\mathrm{m}, \mathrm{n}, \mathrm{z}, \mathrm{v}, \mathrm{j})$ за класичним методом.

Послідовність розрахунку за класичним методом:

1. Визначення хорд:

$\mathrm{H}:=\operatorname{getHords}(\mathrm{M})$.

2. Визначення першої матриці інцидентності для хорд:

$\mathrm{Mb}:=\operatorname{getColumns}(\mathrm{Mwb}, \mathrm{H})$.

3. Визначення віток дерева:

$\mathrm{D}:=\operatorname{getTree}(\mathrm{M}, \mathrm{H})$.

4. Визначення першої матриці інцидентності для дерева графа:
$\mathrm{Ma}:=\operatorname{getColumns}(\mathrm{Mwb}, \mathrm{D})$.

5. Визначення другої матриці інцидентності:

$\mathrm{Nm}:=[-(\mathrm{Ma})]^{-1} \cdot \mathrm{Mb}$,

$\mathrm{N}:=(\operatorname{stack}(\mathrm{Nm}, \operatorname{get} \operatorname{Diag}(\mathrm{M})))^{\mathrm{T}}$.

6. Визначення діагональної матриці опорів:

$\mathrm{Zr}:=\operatorname{diag}(\mathrm{Z})$.

7. Формування різних наборів номерів вузлів для різних балансувальних вузлів:

$\mathrm{W}:=\operatorname{getDiff}(\mathrm{M})$.

8. Визначення задаючих струмів у вузлах за потужностями вузлів:

$\mathrm{J}_{\mathrm{N}}:=\frac{\mathrm{S}}{3^{0.5} \cdot \mathrm{Ub}}$.

9. Проведення розрахунку струмів у вітках за класичним методом:

$\mathrm{Ib}:=\operatorname{getRstate}(\mathrm{M}, \mathrm{N}, \mathrm{Zr}, \mathrm{W}, \mathrm{J})$.

Завдяки функції getJBalance:

$\mathrm{Jb}:=\operatorname{getJBalance}(\mathrm{M}, \mathrm{N}, \mathrm{Zr}, \mathrm{W}, \mathrm{J})$,

встановлено, що для $\boldsymbol{i}$-го балансувального вузла небаланс $\boldsymbol{j}$-го рівняння першого закону Кірхгофа становить:

$$
\begin{aligned}
& \mathrm{Jb}_{j}=\text { const } \neq 0, \text { при } \mathrm{i}=\mathrm{j}, \\
& \mathrm{Jb}_{j}=0, \text { приi } \neq j
\end{aligned}
$$

\begin{tabular}{c|c}
$\mathrm{Nm}:=[-(\mathrm{Ma})]^{-1} \cdot \mathrm{Mb}$ & $\begin{array}{c}\text { for } \mathrm{i} \in 1 . .1+\operatorname{cols}(\mathrm{a})-\operatorname{rows}(\mathrm{a}) \\
\mathrm{b}_{\mathrm{i}} \leftarrow 1\end{array}$ \\
$\mathrm{~N}:=(\operatorname{stack}(\mathrm{Nm}, \operatorname{getNDiag}(\mathrm{M})))^{\mathrm{T}}$ & $\operatorname{diag}(\mathrm{b})$
\end{tabular}

Pис. 5. Побудова другої матриці інцидентності, функція getNDiag(a) 
$\mid \begin{aligned} & \mathrm{k} \leftarrow \operatorname{row}(\mathrm{m}) \\ & \mathrm{q} \leftarrow \operatorname{cols}(\mathrm{m})-\mathrm{k}+1 \\ & \text { for } \mathrm{i} \in 1 . . \mathrm{k} \\ & \\ & \begin{array}{l}\mathrm{My}_{\mathrm{i}} \leftarrow \operatorname{getRows}\left(\mathrm{m}, \mathrm{v}_{\mathrm{i}}\right) \\ \mathrm{A}_{\mathrm{i}} \leftarrow \operatorname{stack}\left(\mathrm{My}_{\mathrm{i}}, \mathrm{n} \cdot \mathrm{z}\right) \\ \mathrm{Jy}_{\mathrm{i}} \leftarrow \operatorname{getRows}\left(\mathrm{j}_{,} \mathrm{v}_{\mathrm{i}}\right) \\ \text { for }^{\mathrm{t}} \in 1 . . \mathrm{q} \\ \mathrm{Jy}_{\mathrm{i}} \leftarrow \operatorname{stack}\left(\mathrm{Jy}_{\mathrm{i}}, 0\right) \\ \mathrm{I}_{\mathrm{i}} \leftarrow\left(\mathrm{A}_{\mathrm{i}}\right)^{-1} \cdot \mathrm{Jy}_{\mathrm{i}}\end{array}\end{aligned}$

a) Функиія getRstate $(m, n, z, v, j)$ $\mid \begin{aligned} & \mathrm{k} \leftarrow \operatorname{row~}(\mathrm{m}) \\ & \mathrm{q} \leftarrow \operatorname{cols}(\mathrm{m})-\mathrm{k}+1 \\ & \text { for } \mathrm{i} \in 1 . . \mathrm{k} \\ & \\ & \begin{array}{l}\mathrm{My}_{\mathrm{i}} \leftarrow \operatorname{getRows}\left(\mathrm{m}_{,} \mathrm{v}_{\mathrm{i}}\right) \\ \mathrm{A}_{\mathrm{i}} \leftarrow \operatorname{stack}\left(\mathrm{My}_{\mathrm{i}}, \mathrm{n} \cdot \mathrm{z}\right) \\ \mathrm{Jy}_{\mathrm{i}} \leftarrow \operatorname{getRows}\left(\mathrm{j}, \mathrm{v}_{\mathrm{i}}\right) \\ \text { for }^{\mathrm{t}} \in 1 . . \mathrm{q} \\ \mathrm{Jy}_{\mathrm{i}} \leftarrow \operatorname{stack}\left(\mathrm{Jy}_{\mathrm{i}}, 0\right) \\ \mathrm{I}_{\mathrm{i}} \leftarrow\left(\mathrm{A}_{\mathrm{i}}\right)^{-1} \cdot \mathrm{Jy}_{\mathrm{i}} \\ \mathrm{Jb}_{\mathrm{i}} \leftarrow \mathrm{m} \cdot \mathrm{I}_{\mathrm{i}}-\mathrm{j}\end{array} \\ & \mathrm{Jb}\end{aligned}$

б) Функиія getJBalance $(m, n, z, v, j)$

Pис. 6. Функція розрахунку струмів у вітках $\operatorname{get} \boldsymbol{R s t a t e ( m , n , z , v , j )}$ та небалансу струмів у вузлах $\boldsymbol{g e t J B a l a n c e}(\boldsymbol{m}, \boldsymbol{n}, \boldsymbol{z}, \boldsymbol{v}, \boldsymbol{j})$ за умови різних балансувальних вузлів

Автоматизація розрахунку струмів за методом рівноважного балансування. У методі рівноважного балансування вузлів пропонується небаланс задаючого струму в одному балансувальному вузлі розподілити рівномірно між усіма вузлами схеми.

Для приведення системи узагальненого рівняння до канонічного вигляду в усі рівняння першого закону Кірхгофа треба додати додаткову змінну рівноважного задаючого струму у формі додаткового стовпця одиниць і додаткового стовпця нулів у матриці, що складена за другим законом Кірхгофа. Це здійснюється завдяки використанню функції addOnes $(a, a d d)$, яка подана на рис. 7.

$$
\mid \begin{aligned}
& \operatorname{imax} \leftarrow \operatorname{rows}(\mathrm{a}) \\
& \operatorname{jmax} \leftarrow \operatorname{cols}(\mathrm{a}) \\
& \mathrm{Mm} \leftarrow \mathrm{a} \\
& \text { for } \mathrm{i} \in 1 . . \operatorname{imax} \\
& \mathrm{Mm}_{1, j \operatorname{jmax}+1} \leftarrow \text { add } \\
& \mathrm{Mm}
\end{aligned}
$$

a) Функиія addOnes (a,add)

$$
\begin{gathered}
\text { Ms }=\operatorname{addOnes}(M, 1) \\
Z s=\operatorname{addOnes}(N \cdot Z r, 0) . \\
A s=\operatorname{stack}(M s, Z s) \\
\text { Is }=A s^{-1} \cdot J \boldsymbol{s}
\end{gathered}
$$

б) Розрахунок за рівноважним методом
Рис. 7. Функція розрахунку небалансу задаючих струмів

Система рівнянь, складена за першим і другим законами Кірхгофа, у матричному вигляді визначається $з$ виразів (див. рис. 7):

$$
\text { Ms }=\mathbf{a d d O n e s}(M, 1) ; Z s=\operatorname{addOnes}(N \cdot Z r, 0) .
$$

Матриця коефіцієнтів узагальненого рівняння формується стикуванням цих двох матриць:

$$
\operatorname{As}=\operatorname{stack}(M s, Z s)
$$

Обчислення значень струмів у вітках відбувається за формулою:

$$
\mathbf{I s}=A \boldsymbol{s}^{-1} \cdot \boldsymbol{J} \mathbf{s}
$$

\section{Приклад розрахунку}

Як приклад розглянемо тестову схему, яка містить 6 вузлів, 8 віток і 3 контури та зображена на рис. 8 .
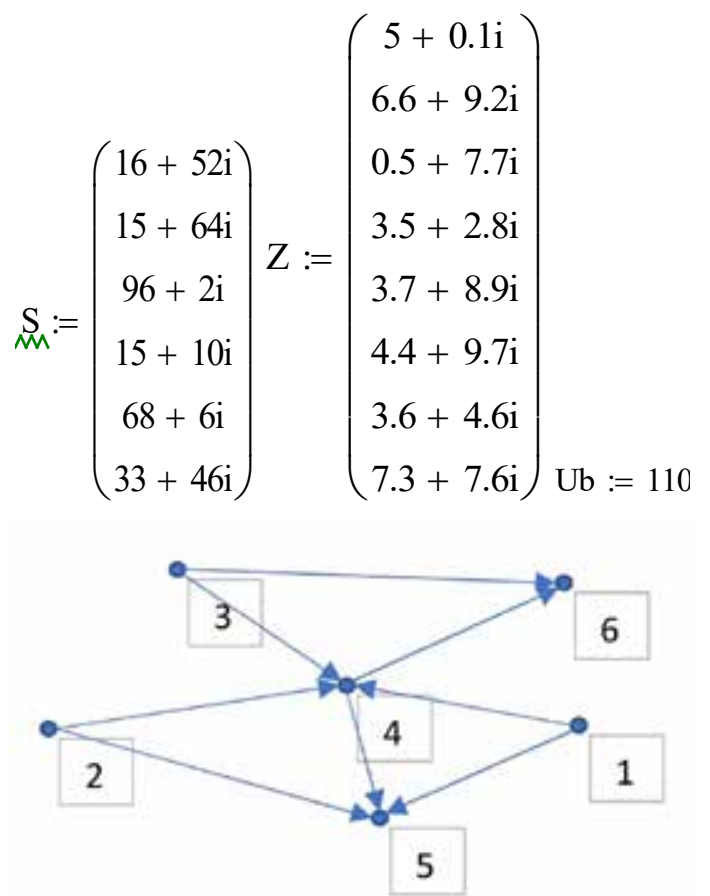

Рис. 8. Вихідні дані розрахунку та розрахункова схема електричної мережі 
Таблиця 1. Результати розрахунку струмів у вітках за умови різних балансувальних вузлів

\begin{tabular}{|c|c|c|c|c|c|c|c|}
\hline \multirow{3}{*}{$\begin{array}{c}\text { Номери } \\
\text { віток }\end{array}$} & \multicolumn{6}{|c|}{ Номери балансувальних вузлів } & \multirow{3}{*}{$\begin{array}{c}\text { Середнс } \\
\text { арифметичне }\end{array}$} \\
\hline & 1 & 2 & 3 & 4 & 5 & 6 & \\
\hline & \multicolumn{6}{|c|}{ Розрахункові значення струмів за умови різних балансувальних вузлів } & \\
\hline 1 & $\begin{array}{c}0,777 \\
+0,676 \mathrm{i}\end{array}$ & $\begin{array}{c}0,0098 \\
-0,093 \mathrm{i}\end{array}$ & $\begin{array}{c}-0,072 \\
-0,306 \mathrm{i}\end{array}$ & $\begin{array}{c}-0,072 \\
-0,306 \mathrm{i}\end{array}$ & $\begin{array}{c}0,133 \\
-0,045 \mathrm{i}\end{array}$ & $\begin{array}{c}-0,072 \\
-0,306 \mathrm{i}\end{array}$ & $\begin{array}{c}0,117 \\
-0,063 \mathrm{i}\end{array}$ \\
\hline 2 & $\begin{array}{c}0,414 \\
-0,0043 i\end{array}$ & $\begin{array}{l}-0,094 \\
-0,18 \mathrm{i}\end{array}$ & $\begin{array}{c}-0,012 \\
+0,033 \mathrm{i}\end{array}$ & $\begin{array}{c}-0,012 \\
+0,033 \mathrm{i}\end{array}$ & $\begin{array}{c}-0,217 \\
-0,228 \mathrm{i}\end{array}$ & $\begin{array}{c}-0,012 \\
+0,033 \mathrm{i}\end{array}$ & $\begin{array}{c}0,011 \\
-0,052 \mathrm{i}\end{array}$ \\
\hline 3 & $\begin{array}{l}-0,089 \\
-0,197 i\end{array}$ & $\begin{array}{c}0,635 \\
+0,099 \mathrm{i}\end{array}$ & $\begin{array}{c}-0,23 \\
-0,155 \mathrm{i}\end{array}$ & $\begin{array}{c}-0,23 \\
-0,155 \mathrm{i}\end{array}$ & $\begin{array}{c}0,179 \\
+0,004 \mathrm{i}\end{array}$ & $\begin{array}{c}-0,23 \\
-0,155 \mathrm{i}\end{array}$ & $\begin{array}{l}0,0057 \\
-0,093 i\end{array}$ \\
\hline 4 & $\begin{array}{l}0,0099 \\
-0,139 i\end{array}$ & $\begin{array}{c}0,561 \\
+0,51 \mathrm{i}\end{array}$ & $\begin{array}{c}0,152 \\
-0,181 \mathrm{i}\end{array}$ & $\begin{array}{c}0,152 \\
-0,181 \mathrm{i}\end{array}$ & $\begin{array}{l}-0,257 \\
-0,34 i\end{array}$ & $\begin{array}{c}0,152 \\
-0,181 \mathrm{i}\end{array}$ & $\begin{array}{c}0,128 \\
-0,085 \mathrm{i}\end{array}$ \\
\hline 5 & $\begin{array}{l}-0,424 \\
-0,053 i\end{array}$ & $\begin{array}{c}-0,424 \\
-0,053 \mathrm{i}\end{array}$ & $\begin{array}{c}0,492 \\
+0,54 \mathrm{i}\end{array}$ & $\begin{array}{c}-0,424 \\
-0,053 \mathrm{i}\end{array}$ & $\begin{array}{c}-0,424 \\
-0,053 \mathrm{i}\end{array}$ & $\begin{array}{c}0,082 \\
+0,163 \mathrm{i}\end{array}$ & $\begin{array}{l}-0,187 \\
+0,082 \mathrm{i}\end{array}$ \\
\hline 6 & $\begin{array}{c}-0,08 \\
+0,042 \mathrm{i}\end{array}$ & $\begin{array}{c}-0,08 \\
+0,042 \mathrm{i}\end{array}$ & $\begin{array}{c}0,28 \\
+0,395 \mathrm{i} \\
\end{array}$ & $\begin{array}{c}-0,08 \\
+0,042 \mathrm{i}\end{array}$ & $\begin{array}{c}-0,08 \\
+0,042 \mathrm{i}\end{array}$ & $\begin{array}{c}-0,586 \\
-0,174 i\end{array}$ & $\begin{array}{c}-0,104 \\
+0,065 \mathrm{i}\end{array}$ \\
\hline 7 & $\begin{array}{c}-0,067 \\
+0,175 \mathrm{i}\end{array}$ & $\begin{array}{c}-0,111 \\
-0,299 \mathrm{i}\end{array}$ & $\begin{array}{c}0,217 \\
+0,179 \mathrm{i}\end{array}$ & $\begin{array}{c}0,217 \\
+0,179 \mathrm{i}\end{array}$ & $\begin{array}{c}-0,444 \\
-0,346 \mathrm{i}\end{array}$ & $\begin{array}{c}0,217 \\
+0,179 \mathrm{i}\end{array}$ & $\begin{array}{c}0,0048 \\
+0,011 \mathrm{i}\end{array}$ \\
\hline 8 & $\begin{array}{c}0,253 \\
+0,199 \mathrm{i}\end{array}$ & $\begin{array}{c}0,253 \\
+0,199 \mathrm{i}\end{array}$ & $\begin{array}{l}-0,106 \\
-0,153 \mathrm{i}\end{array}$ & $\begin{array}{c}0,253 \\
+0,199 \mathrm{i}\end{array}$ & $\begin{array}{c}0,253 \\
+0,199 \mathrm{i}\end{array}$ & $\begin{array}{l}-0,516 \\
-0,529 \mathrm{i}\end{array}$ & $\begin{array}{c}0,065 \\
+0,019 \mathrm{i}\end{array}$ \\
\hline
\end{tabular}

Відповідно до початкових даних результати розрахунку струмів узагальненого рівняння стану за умови почергового вибору різних балансувальних вузлів зведено до таблиці 1.

Отже, значення струмів суттєво залежать від вибору балансувального вузла. Постає необхідність розрахунку за розробленим методом рівноважного балансування вузлів із метою виключення впливу вибору балансувального вузла на результат розрахунку.

Розраховані за розробленим методом рівноважного балансування струми у вітках становлять:

$$
\text { Is }=\left(\begin{array}{c}
0.117-0.063 \mathrm{i} \\
0.011-0.052 \mathrm{i} \\
5.739 \times 10^{-3}-0.093 \mathrm{i} \\
0.128-0.085 \mathrm{i} \\
-0.187+0.082 \mathrm{i} \\
-0.104+0.065 \mathrm{i} \\
4.824 \times 10^{-3}+0.011 \mathrm{i} \\
0.065+0.019 \mathrm{i} \\
0.213+0.157 \mathrm{i}
\end{array}\right)
$$

\section{ОБГОВОРЕННЯ ОТРИМАНИХ РЕЗУЛЬТАТІВ}

Отже, у результаті проведеного розрахунку отримано значення струмів у вітках, які збігаються із середнім арифметичним значенням шести розрахунків із різними балансувальними вузлами, розрахованими за класичним методом.

Загальний небаланс $1,275+0,945 \mathrm{i}$, який розраховано для одного балансувального вузла за класичним методом, рівномірно розподілився між усіма вузлами схеми і становить $1 / 6$ частину від $1,275+0,945 \mathrm{i}$, що дорівнює 0,213+0,157i.

\section{ВИСНОВКИ}

Розроблено новий метод рівноважного балансування потужності електроенергетичної системи, який, на відміну від наявних, виконує розрахунок усталеного режиму без врахування балансувального вузла, що допомагає розподілити наявний небаланс рівномірно за всіма вузлами схеми, а також зменшує похибку розрахунку струмів у вітках, оскільки визначає середньозважений вектор струмів. Структура розробленого алгоритму запропонованого в статті методу є лінійною, а сам метод простий у використанні. Для здійснення рівноважного балансування потужностей вузлів $\mathrm{y} n$ разів зменшується кількість розрахунків порівняно 3 класичним підходом, що є перевагою цього методу. У статті також розроблено засоби автоматизації розрахунків усталеного режиму електричної мережі за класичним і розробленим методами в пакеті прикладних програм MathCAD.

\section{REFERENCES}

[1] Kirilenko O.V., Szegeda M.S., Butkevich O.F., Mazur T.A. (2010) Mathematical modeling in power engineering. Textbook. Lviv : Lviv Polytechnic National University Publishing House. 608 p. [in Ukrainian].

[2] Lezhnyuk P.D., Lesko V.O., Vidmysh V.A. (2012) Influence of balancing unit selection on power loss sensitivity in UES. International scientific and technical journal. Information technology and computer engineering. № 3. Pp. 91-95. [in Ukrainian]. 
[3] Merkuryev G.V., Shargin Yu.M. (2008) Stability of power systems. Calculations. Volume 2. SPb. : SMO "Energy Training Center”. 376 p. [in Russian].

[4] Lokhanin E.K., Moroshkin Yu.V., Rossovsky K.L. et al. (2013) Methodology for calculating steady-state operating modes of power systems taking into account frequency changes. M. : Electricity. № 3. Pp. 10-18. [in Russian].

\section{СПИСОК ЛІТЕРАТУРИ}

[1] Кириленко О.В., Сегеда М.С., Буткевич О.Ф., Мазур Т.А. (2010) Математичне моделювання в електроенергетиці : підручник. Львів : Видавництво НУ «Львівська політехніка». 608 с.

[2] Лежнюк П.Д., Лесько В.О., Видмиш В.А. (2012) Вплив вибору балансуючого вузла на чутливість втрат потужності в ЕЕС. Міжнародний науково-технічний журнал. Інформаційні технологї̈ та комп 'ютерна інженерія. № 3. С. 91-95.

[3] Меркурьев Г.В., Шаргин Ю.М. (2008) Устойчивость энергосистем. Расчеты. Т. 2. Санкт-Петербург : НОУ «Центр подготовки кадров енергетики». 376 с.

[4] Лоханин Е.К., Морошкин Ю.В., Россовский К.Л. и др. (2013) Методика расчётов установившихся режимов работы энергосистем с учётом изменения частоты. Москва : Электричество. № 3. С. 10-18.

(C) С. В. Бевз, С. М. Бурбело, В. В. Войтко Дата надходження статті до редакції: 07.12.2020 Дата затвердження статті до друку: 18.12.2020 